\title{
Evaluation of Student Satisfaction in Using the Learning Management System for Online Learning at XYZ University
}

\author{
Yulyanty Chandra ${ }^{1}$, TogarAlamNapitupulu ${ }^{2}$ \\ ${ }^{12}$ Information Systems Management Department, BINUS Graduate Program-Master of Information \\ Systems Management,
}

\author{
Bina Nusantara University, Jakarta, Indonesia 11480
}

\begin{abstract}
This research is to analyse what factors that influence the student satisfaction with the learning management system and how much influence do these factors have on student satisfaction with the use of the learning management system. This research aim was to find if there is a direct influence from the system quality, information quality, service quality, and perceived ease of use into the user satisfaction and whether there is an indirect influence from System use to the User satisfaction toward learning management system. The analytical method for analyse regression with the estimation of PLS Method, this research took sample of 99 students at XYZ University in Information system online learning, major study for undergraduate students. The results show that the indirect effect through system use are not significant; however the perceived ease of use and system quality turn out significant affecting the student satisfaction. Perceived ease of use is the most high factor for affecting the satisfaction of the students to use Learning Management System(LMS) as the media for online learning.
\end{abstract}

Keywords: Online learning, SmartPLS, Learning Management System, Partial Least Square, E-learning

\section{INTRODUCTION}

Education is one of the important process in the progress of a country development, as stated by Nelson Mandela, that, "Education is the most powerful weapon which you can use to change the world". Education in its role must be able to produce quality future generations of the nation and be able to create real work that is useful for world change. As we know, traditional education that has existed so far is the Face to face (onsite) class between teachers and students who are gathered in a room called a classroom. Where the teacher stands in front all students to teach the material to be discussed in class. For this traditional teaching method, students and teachers are strict by a schedule, they have to meet each other, in order to present both at the same time and day. But the student will be motivatedwith the online learning method by using the media seen on the website becauseit shows the attraction through website, which is more attractive, motivate the whole learningprocess to besucceed, compared with theonsite lectures. Students will be more happy and having effective learning with the use of the learning management system if the system can provide comfort in use and can support student learning performance in the future. XYZ University which runs Online Learning in Jakarta, makes it easy for students who came from different cities or countries, who cannot participate in learning activities in class (onsite), students can take part in online learning. With the flexibility of time and place,also produce the same graduates as face-to-face classes. Students will be guided by XYZ University Online lecturers who are not only homebased in Jakarta, but outside Jakarta via video conference. The research has a purpose to determined what factors that will influence the student'ssatisfaction by using thethe learning management system(LMS) and how much influence do these factors have on student satisfaction and the use of the learning management system.

\section{LITERATURE REVIEW}

The theories about learning management system, information quality, system quality, service quality and perceived ease of use, have relevance to system use and student satisfaction (user satisfaction) with Learning Management Systems (LMS).The following shows several literature reviews and the results of previous research that support and are related to research variables, namely information quality, system quality, service quality, perceived ease of use, system use, also user satisfaction.

\subsection{Learning Management System (LMS)}

LMS or better known as Learning Management System (LMS) is a software application, created to help the online learning process, provide with the material videos, forum posting, video conferences, messages with 
private chat, materials and quiz. Learning Management System (LMS) is comprehensively integrated with various features for course delivery and management. Also, effective and flexible to use for the online learning students (Simanullang\&Rajagukguk, 2020), from the statement above, the authors conclude that LMS is software used for online teaching and learning activities that is connected to the internet, and is integrated with the management of material, values and quizzes.

\subsection{Information Quality}

The quality of information in a long tradition refers to the form of the results of the system, namely the quality of information produced, where the specifics are in the form of reports. The characteristics and types desired are such as accuracy, precision, currency, reliability, completeness, conciseness, relevance, understanding, interpretation, timeliness, comparison and format. Uses six measurement scales as follows: completeness, precision, reliability, data is always updated (currency), and the form of the output (format of output) (Iivari, n.d.).

\subsection{Service Quality}

Service quality as a comparison of expectation customer towards the perception of the right services they hope to receive. There are three indicators that influence service quality, namely assurance, the quality assurance provided by the system, empathy (empathy system), namely the system's concern for the users, the responsiveness system, also for the quality of the system's reacts to actionperformed by the user(DeLone\& McLean, 2004).

\subsection{Perceived ease of use}

The view of ease of application (Perceived ease of use) is the level where a person believes that if the use of a certain system will be able to help and reduce the person's effort in doing his job, routine use and collaboration between the user and the system will be able to show ease of use. If the system is routine and always used by users, the system will be better known and easier to use by its users (Desanciis\&Disseiitation, n.d.).

\subsection{System Use}

A system usage contains the most crucial indicatorfor the success of a system. Quoting (DeLone\& McLean, 2004)that the naturity, the quality and suitability of system use are very important. Meanwhile, a standardmeasure of the time is inadequate. System use construct has also been measured as the construct "possible to use" and "intention to use" (Fang et al., 2011).

\subsection{User satisfaction}

From the result of their research is that the pathway relation between communication quality has the significant effect with user satisfaction. Quality of communication sure do help the users to share and integrated theinformation, providing responses, negotiable and integrated between system use. This could increase the user satisfaction with the e-learning method(Wardhani, 2017).

\subsection{Research Model}

In a previous study(Freeze et al., 2010), the researchconducted with the structural models and measurements, using the sample of 674 students from Midwestern university. The end result showed both the information quality and system quality had a significant factor on the system use and user satisfaction.

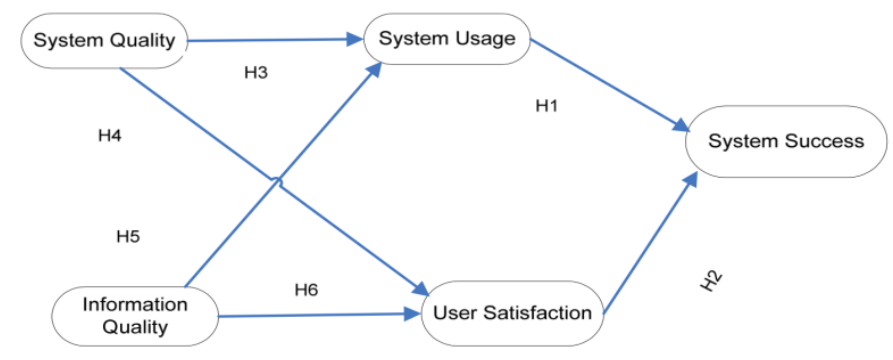

Fig 1. Research Framework 1 
From Figure 1, the path coefficient in $\mathrm{H} 2$ that is user satisfaction toward system success, had the highest effect on system success. Result that both information and system quality were highly affectingthe user satisfaction. And bothvariable for system quality and information quality having a high impact on user satisfaction and system use. Also, the output showed the user satisfaction, compared to system use, had a more strong impact on system success.

Other previous study (Jafari et al., 2016)the object for this research were 465 creative technology for undergraduate students of Limkokwing University. The research sampling was analysedfrom the number of students in each faculty. Quantitative data were includedwith a questionnaire.

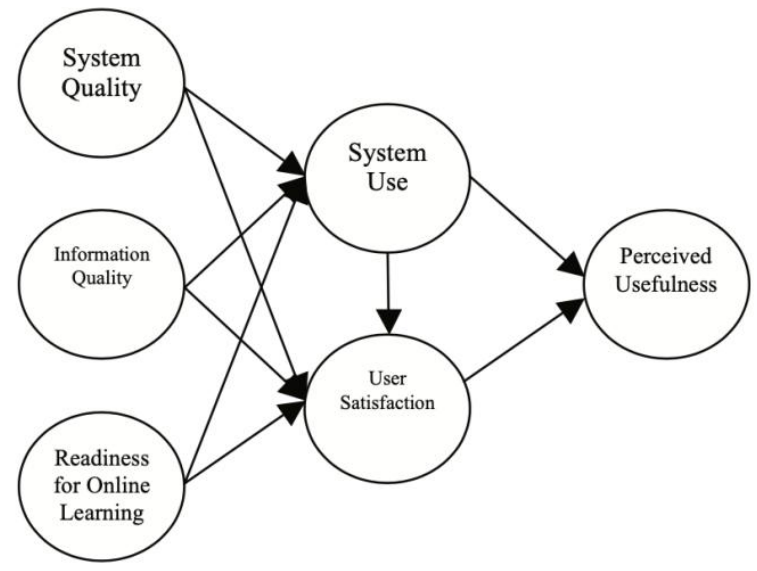

Fig 2. Research Framework 2

From the Figure 2, shows the data analysis result is all the path from the independent and dependentvariables were correlated, but not with the readiness on online learning and system use. Highest influential pathway is the quality of information about user satisfaction,perceived usefulness and the minim influential is readiness for online learning, system use, and perceived usefulness.

Also, from other previous study (Ohliati\& Abbas, 2019), the study was conducted to determine whether there was an effect of information quality, system quality,service quality,perceived ease of usefulness, perceived ease of use and communication quality on the student's satisfaction with the Learning Management System (LMS). Theresearch used 100 students as respondents with analytical method that is used for the research, SmartPLS.

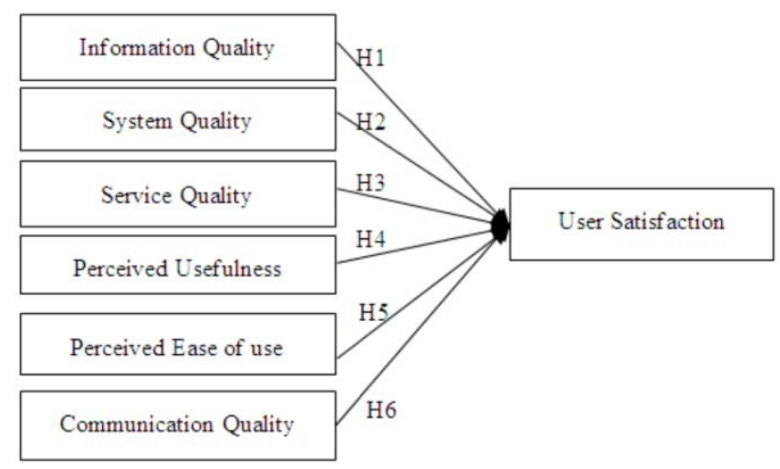

Fig3. Research framework 3

The results from Figure 3 showed theinformation quality, service quality, and perceived ease of useare significantlyaffecttowardsthe student's satisfaction. The service quality got the highest effect in affecting student satisfactionusing the Learning Management System.

Based on overall analyze of the previous study frameworks above, the authormeets with the research framework paradigms for the related variables used, thereareSystem Quality (SQL), Information Quality (IQ), service 
quality (SQ), Perceived ease of use (PU), System use (SU) and user satisfaction (US):

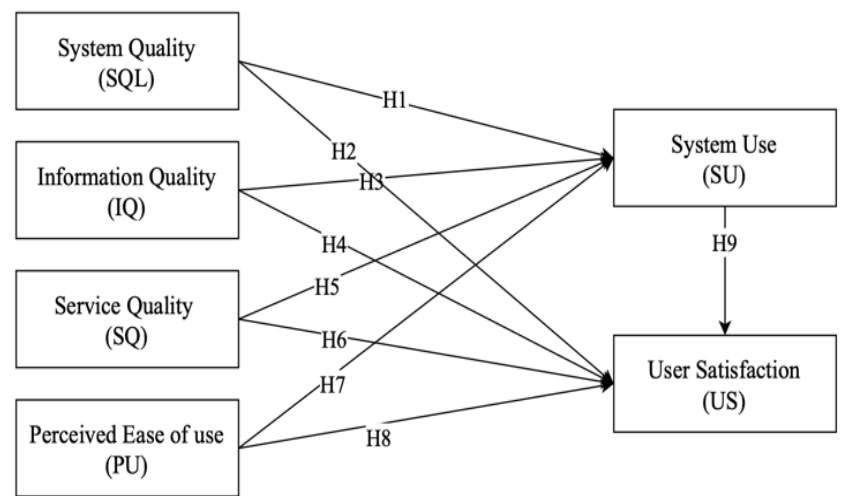

Fig4. Research Framework 4

For the research framework on the Figure 4, based on the above literature review and from the research framework, the following hypothesis can be noticed for:

H1: System Quality has the significant effect on System use

$\mathrm{H} 2$ : System Quality has the significant effect on user satisfaction

H3: Information quality has the significant effect on system use

H4:Information Quality has the significant effect on user satisfaction

H5: Service Quality has the significant effect on system use

H6: Service Quality has the significant effect on user satisfaction

H7: Perceived Ease of use has the significant effect on System use

H8: Perceived Ease of use has the significant effect on User satisfaction

H9: System use has the significant effect on User satisfaction

We will analyze whether there is a significant indirect affect from System use to the User Satisfaction (line H9). If it is significant, the analyze will continue with the line $\mathrm{H} 1, \mathrm{H} 2, \mathrm{H} 3, \mathrm{H} 5, \mathrm{H} 7$ and $\mathrm{H} 9$. If the $\mathrm{H} 9$ is not significant, then it has no indirect affect. And the analyze will only focuswith the line H2, H4, H6 and H8.

\section{METHODOLOGY}

The research will test the validity and reliability by using questionnaire for the data collection. Following with the next step is to interpretation and analyse the collected data by using descriptive statistic analyse and inferential statistic. The sample took 99 online students who are still registered as an active studentsof undergraduate students of Information Systems study programat XYZ University in Jakarta city. The questionnaire is given with google form using Likert scale from 1 until 5. Using Partial Least Square (PLS) as the inferential statistics method and had been analyse with the help of the SmartPLS 3.0 program. In this section, each variable will be described in an equation that connects these variables with the indicators, in order to define the latent variables in this study.

\section{RESULT AND DISCUSSION}

\subsection{Measurement model}

The validity and reliability are the first step to take. The analysis carried out with outer model like discriminant validity, convergent validity,composite reliability (CR),also AVE (Average Variance Extracted). The framework research added with 23 indicator items and 6 dimensions for the characteristics of the student's satisfaction. The result showed in the loading factor $(\lambda)$, which are bigger than 0,5 . Means all indicator already fulfilled the terms: 
TABLE I. RESULT FROM OUTER MODEL

\begin{tabular}{|c|c|c|c|c|}
\hline Construct & Dimension & $\lambda$ & CR & AVE \\
\hline \multirow{5}{*}{ System Quality (SQL) } & Navigation & 0,764 & \multirow{5}{*}{0,848} & \multirow{5}{*}{0,528} \\
\hline & Functionality & 0,742 & & \\
\hline & Response time & 0,777 & & \\
\hline & Flexibility & 0,626 & & \\
\hline & Security & 0,713 & & \\
\hline \multirow{5}{*}{ Information Quality (IQ) } & Accuracy & 0,849 & \multirow{5}{*}{0,925} & \multirow{5}{*}{0,711} \\
\hline & Relevance & 0,859 & & \\
\hline & Availability & 0,841 & & \\
\hline & Usability & 0,799 & & \\
\hline & Timeliness & 0,868 & & \\
\hline \multirow{4}{*}{ Service Quality (SQ) } & Empathy & 0,847 & \multirow{4}{*}{0,892} & \multirow{4}{*}{0,67} \\
\hline & Reliability & 0,885 & & \\
\hline & Responsive & 0,866 & & \\
\hline & Tangible & 0,675 & & \\
\hline \multirow{4}{*}{ Perceived ease of use (PU) } & Improving performance & 0,924 & \multirow{4}{*}{0,954} & \multirow{4}{*}{0,839} \\
\hline & Increasing Productivity & 0,906 & & \\
\hline & Easier study & 0,898 & & \\
\hline & Overall usefulness & 0,935 & & \\
\hline \multirow{2}{*}{ System Use (SU) } & Possible to use & 0,766 & \multirow{2}{*}{0,820} & \multirow{2}{*}{0,696} \\
\hline & Intend to use & 0,898 & & \\
\hline \multirow{3}{*}{ User Satisfaction (US) } & LMS Experience & 0,935 & \multirow{3}{*}{0,936} & \multirow{3}{*}{0,831} \\
\hline & LMS Performance & 0,922 & & \\
\hline & LMS Learning tool & 0,876 & & \\
\hline
\end{tabular}

\subsection{Structural Model}

The research examine structure model for theusefull of the independent variable to show the dependent variable and the significancesfor relationship line. This is to find out how much the independent variable is capable ofdescribe the dependent variable. UsingSmartPLS 3.0 program to help, the R - Square output is found as follows:

TABLE 2. R - SQUARE OUTPUT

\begin{tabular}{|l|l|l|}
\hline & R-Square & R-Square Adjusted \\
\hline System Use & 0.683 & 0.669 \\
\hline User Satisfaction & 0.721 & 0.706 \\
\hline
\end{tabular}

The value of R-Square System Use is 0.683 for the System Use construct, which shows the influence between System quality, Information quality, service quality, perceived ease of use on System Use by $68.3 \%$ and the remaining $31.7 \%$ is influenced by other variables besides in this research. As for the R Square User Satisfaction value of 0.721 for the User Satisfaction construct, which shows the influence between System quality, Information quality, service quality, perceived ease of use on User Satisfaction by $72.1 \%$ and the remaining $27.9 \%$ influenced by other variables. other than in this research.

\subsection{Hypothesis Testing}

Hypothesis testing in the study was carried out with $\mathrm{p}$-value, with the p-value $\leq 0.05$ (alpha $5 \%$ ) was obtained, the result shows that exogen latent variable had the significant effect on the endogenous latent variable (H0 was rejected), and if the p-value was > 0, 05.It is concluded that the exogenlatent variable has no significant effect on the endogenous latent variable (H0 is accepted). The p-value test can be seen as follows: 
TABLE 3. STUDENTSATISFACTION EVALUATION MODEL HYPOTHESIS

\begin{tabular}{|c|c|c|c|c|l|l|}
\hline No & Hypothesis & $(\boldsymbol{\beta})$ & $\begin{array}{c}\text { T- } \\
\text { Statistics }\end{array}$ & $\begin{array}{c}\text { P - } \\
\text { Values }\end{array}$ & Result & $\begin{array}{l}\text { Effect } \\
\text { Size }\end{array}$ \\
\hline H1 & SQL -> SU & 0.106 & 2.630 & 0.009 & Support & Large \\
\hline H2 & SQL -> US & 0.105 & 2.884 & 0.004 & Support & Large \\
\hline H3 & IQ -> SU & 0.111 & 0.014 & 0.989 & $\begin{array}{c}\text { Not } \\
\text { Support }\end{array}$ & Small \\
\hline H4 & IQ -> US & 0.123 & 0.605 & 0.546 & $\begin{array}{c}\text { Not } \\
\text { Support }\end{array}$ & Medium \\
\hline H5 & SQ -> SU & 0.090 & 0.939 & 0.348 & $\begin{array}{l}\text { Not } \\
\text { Support }\end{array}$ & Medium \\
\hline H6 & SQ -> US & 0.103 & 0.711 & 0.478 & $\begin{array}{c}\text { Not } \\
\text { Support }\end{array}$ & Medium \\
\hline H7 & PU -> SU & 0.095 & 5.399 & 0.000 & Support & Large \\
\hline H8 & PU -> US & 0.116 & 3.472 & 0.001 & Support & Large \\
\hline H9 & SU -> US & 0.108 & 0.805 & 0.421 & $\begin{array}{l}\text { Not } \\
\text { Support }\end{array}$ & Medium \\
\hline
\end{tabular}

H1: System Quality shows significantly affect from System use, because of the System Quality p-value is 0.009 , that less than 0.05 . With original sample is about 0.109 , means the increasing of system quality for 1 unit is affecting the system use of 0.106 . for that, the research proved similarwith theprevious research(Freeze et al., 2010) which states the service quality affect significantly to the System User.

$\mathrm{H} 2$ : System Quality also shows significantly affect the user satisfaction because of the system quality p-value is 0.004 that is smaller from 0.05 . With original sample value is 0.104 , which means system quality increasing of 1 unit that will affect the student satisfaction of 0.105 units. This research also the same with the last research(Ohliati\& Abbas, 2019), which states the service quality affect significantly to the User Satisfaction.

H3: Information quality shows to be not significant effect on System Use because the p-value for service quality is 0.989 , that is provedmore than 0.05 . Means the information quality does notaffecting the system use of learning management system.

H4: Information quality tested to be not significant effect on User satisfaction as a result p-valuefor service quality is 0.546 , that is bigger from 0.05 . It means theinformation quality does not have an effect towards the student satisfaction for having learning management system for learning process.

H5: Service quality proved to be not significant on System Use as a result of p-value service quality is 0.348 , larger than0.05. Italso means that Service Quality issue is not affecting the System use with learning management system.

H6: Service quality proved to be not significanttoward the user satisfactions,because service quality's p-value is 0.478 larger than 0.05, which means it is not affectingstudent's satisfaction in using Learning Management System.

H7: Perceived ease of use proved significantly have an effect on System Use as a result, based on the service quality's p-value is 0.000 , that is less than 0.05 . The original sample's worth is 0.095 , means that if there's a rise Perceived easy use of one unit can have an effect on system use of 0.095 units. This analysis results have the same result from the previous research(Jafari et al., 2016) that states Perceived easy use have an effect on considerably to the System Use

H8: Perceived ease of use also significantly proved affect the User satisfaction from theservice quality's p-value is 0.001 , it islessthan 005 . Also with the original sample's value is 0.116 , means that if it has a rise for Perceived 
ease of use of 1 unit affecting the student satisfaction's for 0.116 units. The result of this research is the same with the previous research(Ohliati\& Abbas, 2019) which states the perceived ease of use affect significantly with the user satisfactiontowards learning management system.

H9: System use to User satisfaction, for indirect effect from proved to be insignificantly affect because the pvalue is 0.421 , that is more bigger from 0.05 . It is proved the system use doesnot affecting the student's satisfaction in using learning management system.

Whole nine hypotheses have been tested, and because there is no indirect significant effect from System Use (SU)towardsthe user satisfaction (US), the research only focuses on Hypotheses H2, H4, H6 and H8. Where the significant hypothesis results are H2 (System Quality) has been proven significantly affect theuser satisfaction and H8 (perceived ease of usealso proved affecting the user satisfaction).

\section{CONCLUSION AND RECOMMENDATION}

We can take conclusion from the research above thatthere are only two variables that affect student satisfaction with the user satisfaction in using the Learning Management System (LMS), that are System Quality (SQ) and Perceived ease of use (PU) because p-value are $\leq 0,05$. From the previous test results, it was found a new research model that affects student satisfaction with LMS as seen from the table 3, (H2) System Quality has a significant towards User Satisfaction for 0,105 and (H8) Perceived ease of use has a significant towards the user satisfaction for 0,116 . This overall result shows the perceived ease of use had the high significant variable towards student's satisfaction in using learning management system (LMS) for studying. Therefore, the recommendation for the research is LMS must improve the quality of its performance so that it is more quick to accessed and make various more attractive features so that it can help students in supporting the learning process, also improving the ease of using the LMS, so that students are more comfortable and helped in using the LMS as a learning platform.

\section{REFERENCES}

1. Ohliati, J., \& Abbas, B. S. (2019). Measuring student'ssatisfaction in using learning management system. International Journal of Emerging Technologies in Learning (iJET), 14(04), 180-189.

2. DeLone, W.H., \& McLean, E.R. (2004). Measuring e-Commerce

Success: Applying the DeLone\& McLean Information Systems Success Model. Int. J. Electronic Commerce, 9, 31-47.

3. Jafari, S.M., Salem, S.F., Moaddab, M.S., \& Salem, S.O. (2015). Learning Management System (LMS) success: An investigation among the university students. 2015 IEEE Conference on e-Learning, $e$ Management and e-Services (IC3e), 64-69.

4. Freeze, R.D., Alshare, K.A., Lane, P., \& Wen, H.J. (2010). IS Success Model in E-Learning Context Based on Students' Perceptions. JISE, 21, 173-184.

5. Iivari, J. 2005. An Empirical Test of the Model of Information System Success. DATA BASE Adv. Inf. Syst. Vol. 36(2): 8-27.

6. Swaid, S. I., \& Wigand, R. T. (2009).Measuring the quality of e-service: Scale development and initial validation. Journal of Electronic Commerce Research, 10(1), 13-28.

7. DeSanctis, G. L. (1982). An examination of an expectancy theory model of decision support system use (Doctoral dissertation, Texas Tech University).

8. Fang, Y. H., Chiu, C. M., \& Wang, E. T. (2011). Understanding customers' satisfaction and repurchase intentions. Internet research.

9. Wardhani, N. K. (2017). Influence of competence, transformational leadership, social capital and performance on employee careers. IJHCM (International Journal of Human Capital Management), 1(02), 81-94

10. Simanullang, N. H. S., \&Rajagukguk, J. (2020, February). Learning Management System (LMS) Based On Moodle To Improve Students Learning Activity. In Journal of Physics: Conference Series (Vol. 1462, No. 1, p. 012067). IOP Publishing. 